\title{
Fault model of the 2007 Noto Hanto earthquake estimated from coseismic deformation obtained by the distribution of littoral organisms and GPS: Implication for neotectonics in the northwestern Noto Peninsula
}

\author{
Yoshihiro Hiramatsu $^{1}$, Kazuyoshi Moriya ${ }^{2}$, Takahiro Kamiya ${ }^{1}$, Michio Kato ${ }^{1}$, and Takuya Nishimura ${ }^{3}$ \\ ${ }^{1}$ Graduate School of Natural Science and Technology, Kanazawa University, Kakuma, Kanazawa, Ishikawa 920-1192, Japan \\ ${ }^{2}$ Department of Earth Sciences, Faculty of Science, Kanazawa University, Kakuma, Kanazawa, Ishikawa 920-1192, Japan \\ ${ }^{3}$ Geography and Crustal Dynamics Research Center, Geographical Survey Institute, Kitasato-1, Tsukuba 305-0811, Japan
}

(Received September 5, 2007; Revised April 2, 2008; Accepted July 1, 2008; Online published October 15, 2008)

\begin{abstract}
We investigate the coseismic vertical crustal movement along the northern and western coast of the Noto Peninsula caused by the Noto Hanto earthquake on March 25, 2007, from the distribution of supra-, mid- and infra-littoral organisms. The highest uplift of $44 \mathrm{~cm}$ is observed at Akakami and the maximum subsidence of $8 \mathrm{~cm}$ at Fukami. We construct a rectangular fault model with a uniform slip in elastic half-space using both the coseismic vertical displacement estimated from the distribution of these organisms and the coseismic crustal deformation obtained by GPS. The model shows a reverse fault with a right-lateral slip of $1.3 \mathrm{~m}$ in a $18.6 \mathrm{~km} \times 14.5 \mathrm{~km}$ area. The seismic moment is $1.0 \times 10^{19} \mathrm{~N} \mathrm{~m}\left(M_{\mathrm{W}} 6.6\right)$ using a rigidity of $30 \mathrm{GPa}$. The geometry of the source fault is consistent with the distribution of aftershocks and active faults, and the fault is restricted to the central area of the aftershock area. Relationships among the fault, the distribution of aftershocks, active faults, and geological blocks around the source area suggest that geological structures restrict the fault size of the earthquake. By considering an inclined altitudinal distribution of marine terraces and the coseismic vertical crustal deformation detected in this study, we estimate that the recurrence of earthquakes during the past $120 \mathrm{kyr}$ would produce a vertical crustal deformation of $\sim 12 \mathrm{~m}$ and the background tectonic uplift would reach $\sim 28 \mathrm{~m}$.
\end{abstract}

Key words: Noto Hanto earthquake, uplift, midlittoral organism, geological structure, fault model, active fault.

\section{Introduction}

The Noto Hanto earthquake ( $\left.M_{\mathrm{JMA}} 6.9\right)$ occurred at 9:41 (JST) March 25, 2007 at a depth of $11 \mathrm{~km}$ beneath the west coast of the Noto Peninsula, central Japan (Fig. 1). This is historically the first $M \sim 7$ earthquake that has hit the Peninsula and also historically the first earthquake that has caused strong ground motion, with the Japan Meteorological Agency (JMA) measuring seismic intensity in 6 upper in the Peninsula.

From the distribution of the aftershocks reported by JMA, the source area of the earthquake is inferred to be located beneath both the sea and the land areas across the coastline of the western Noto Peninsula (Fig. 1). The source mechanism of the earthquake is estimated to be a reverse fault with a right-lateral slip from the moment tensor inversion of long-period seismic waves (Hoshiba, 2007; Takeda et al., 2007). This fault movement caused the coseismic crustal deformation, as reported by the Geographical Survey Institute (GSI) from continuous GPS observation (GSI, 2007a). This crustal deformation is also confirmed by synthetic aperture radar interferometric analysis (InSAR) (Fukushima et al., 2008; Ozawa et al., 2008) and leveling results (GSI, 2007b).

From the aftershock distribution, the source fault is in-

Copyright (c) The Society of Geomagnetism and Earth, Planetary and Space Sciences (SGEPSS); The Seismological Society of Japan; The Volcanological Society of Japan; The Geodetic Society of Japan; The Japanese Society for Planetary Sciences; TERRAPUB. ferred to be a plane with a strike of nearly northeast to southwest and a dip down to southeast (Fig. 1). Figure 2 shows a temporal variation of the distribution of the aftershocks based on the JMA catalogue. Most of the aftershocks within $1 \mathrm{~h}$ after the mainshock occurred in the source fault estimated in this study (Fig. 2(a)). The aftershock area broadened from the central area and extended towards the southwestern and then northeastern areas with time. This expansion occurred in the regions where Coulomb failure stress increased (Toda, 2008). From the aftershock distribution for the entire day after the mainshock, we find a gap of aftershocks between the northeastern and the central areas and another gap between the central and the southwestern areas (Fig. 2(b)). We also recognize a change in the strike of the distribution of the aftershocks; it is nearly NE-SW in the central area, whereas it is nearly ENE-WSW in the southwestern area. The distribution of the aftershocks can, thus, be divided into three sub-areas, the southwestern, the central, and the northeastern areas (Fig. 2(b)).

The Noto Peninsula is mainly composed of Oligocene $\sim$ Early Miocene volcanic rocks and post Oligocene sedimentary rocks (Kaseno, 1993; Kato, 2001; Fig. 3). The back arc basin of the Japanese islands, which now contains the Japan Sea, started to be rifted at the Oligocene. The volcanic rocks in the Noto Peninsula erupted during this rifting event, and the rifting ceased at the Middle Miocene. After the cease of the rifting, shallow marine and offshore sediments were deposited on 


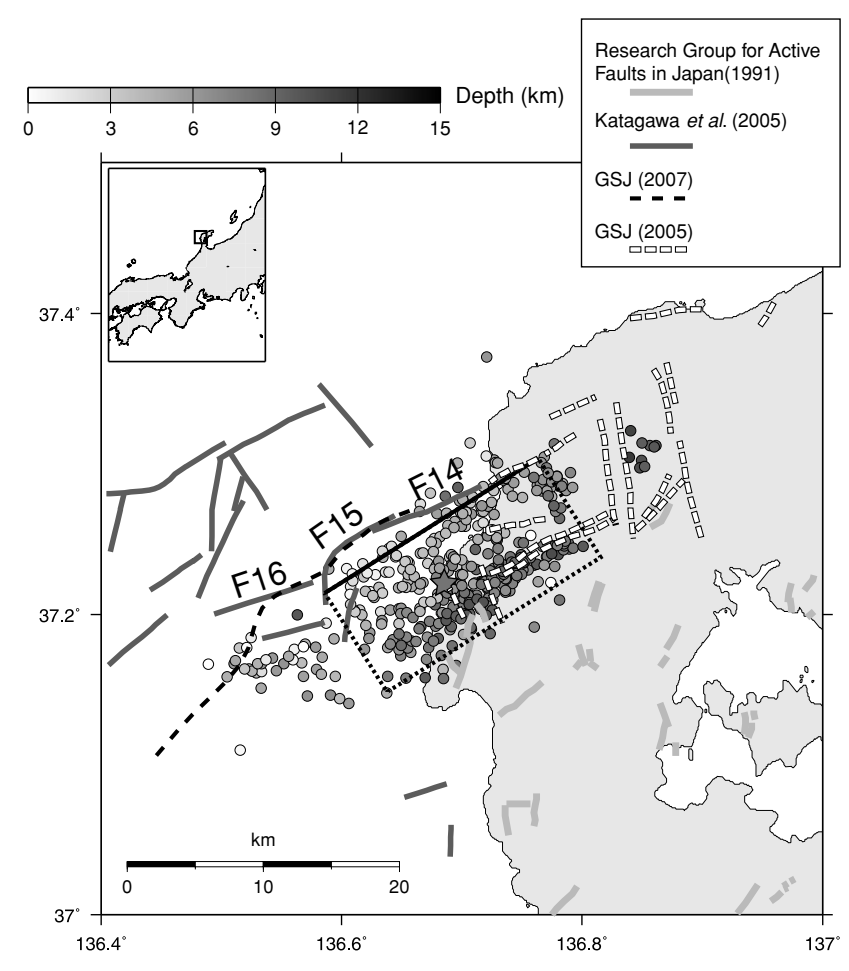

Fig. 1. Distribution of active faults (Research Group for Active Faults in Japan, 1991; Katagawa et al., 2005; GSJ, 2007a), geological faults (GSJ, 2005), and aftershocks ( $M \geq 2$ ) (circles) within 1 day after the mainshock reported by JMA. The dotted rectangle with the solid line as the upper edge indicates the location of the source fault estimated in this study. The epicenter of the mainshock is represented by a star. The source depth of the aftershock is represented by gray scale.

and around these volcanics. While normal faults formed around the Noto Peninsula during this rifting, those normal faults turned to reverse faults after the cease of the rifting due to the compressive stress associated with the forearc subduction (Katagawa et al., 2005). The distribution of geological faults and active faults around the source area are shown in Fig. 1. Geological faults with NE-SW and $\mathrm{N}-\mathrm{S}$ trends can be widely recognized (Geological Survey of Japan (GSJ), 2005). Some active faults have been reported around the aftershock area on land (Research Group for Active Faults in Japan, 1991) and on the seafloor (Katagawa et al., 2005; GSJ, 2007a). We eliminate the F8, F9, and F10 faults of Katagawa et al. (2005) because they have been inactive since the late Pliocene and hence do not match the definition of the active fault of Research Group for Active Faults in Japan (1991). In addition to these active faults, marine terraces are well developed in a large part of the Noto Peninsula. Based on altitude mapping of these marine terraces, Ota and Hirakawa (1979) found the discontinuous distribution of those marine terraces. The boundaries of this discontinuity are also consistent with edges of the mountain ranges. Ota and Hirakawa (1979) thus concluded that the Noto Peninsula is composed of a few tectonic blocks (Fig. 3). These blocks are characterized by their tilting down towards the southeast. The movement of active faults on the seafloor along northern and western coast off the Noto Peninsula has been suggested to be responsible for the tilting (Katagawa et al., 2005).
The mass mortality of littoral organisms has been used to analyze the coseismic vertical displacement of inter-plate earthquakes (Bodin and Klinger, 1986; Carver et al., 1994; Ortlieb et al., 1996; Rajendran et al., 2007). Because sessile organisms settled in mid- and infralittoral zones cannot survive desiccation, a vertical extent of mortality of these organisms reveals the coseismic vertical displacement. For the intra-crustal earthquakes, Awata et al. (2008) was the first to use the dry out height of midlittoral organisms to demonstrate the coseismic uplift and subsidence caused by the Noto Hanto earthquake. Using this approach, we can make dense measurement of the coseismic vertical crustal deformation induced by the Noto Hanto earthquake, in particular at the region above the source area.

In this paper, we report our measurements of coseismic vertical displacement using the distribution of supra-, mid-, and infralittoral organisms and construct a fault model from these measurements together with the coseismic crustal deformation obtained by continuous GPS observation. The sites of our observations are distributed across the source area, providing a good constraint for the modeling. We discuss relationships among the estimated fault model and the distribution of the aftershocks, active faults, and geological structures since the late Pleistocene in this region. Our measurements of the distributions of littoral organisms were first made 1 week after the earthquake in April 2007, and those data are supplemented with additional data obtained in May 2007.

\section{Data}

\subsection{The distribution of midlittoral and infralittoral or- ganisms}

We selected 32 sites for analyses of the coseismic vertical crustal movement using the distribution of littoral organisms (Fig. 4). The total coastal area surveyed extends about $100 \mathrm{~km}$, between Takahama and Noroshi. Of those 32 sites, 25 sites represent quays of fishing ports, and the remaining seven sites are rocky shores. Observed sites are located along the western and northern coasts of the Noto Peninsula (Fig. 4). While the sites in the northern coast between Wajima and Suzu are scattered, those between Togi and Fukami, where significant vertical crustal deformations was expected, are densely distributed.

2.1.1 Measurement method for littoral organisms Sessile organisms inhabited in a littoral zone of rocky shores show a clear zonation in their highest distribution on rocks or quays (Stephenson and Stephenson, 1949, 1972). This universal feature of zonation is also observed along the coastline of the Noto Peninsula (Fig. 5(a)). In the Noto Peninsula, the highest distribution of oysters is comparable to that of sea lettuces on the single quay, and represents a midlittoral zone (Plate 1(D)). Their highest distribution is close to the tide level at high tide. A supralittoral zone and an infralittoral zone are characterized by lichen and cyanobacteria and by gulfweeds and kelp, respectively. We mainly selected oysters attached on a vertical quay within a local fishing port. Because quays in the fishing port are protected from the splash and swell of the ocean, utilizing those oysters minimizes a possible error in measurements. In contrast, marine plants and cyanobacteria were used at rocky 


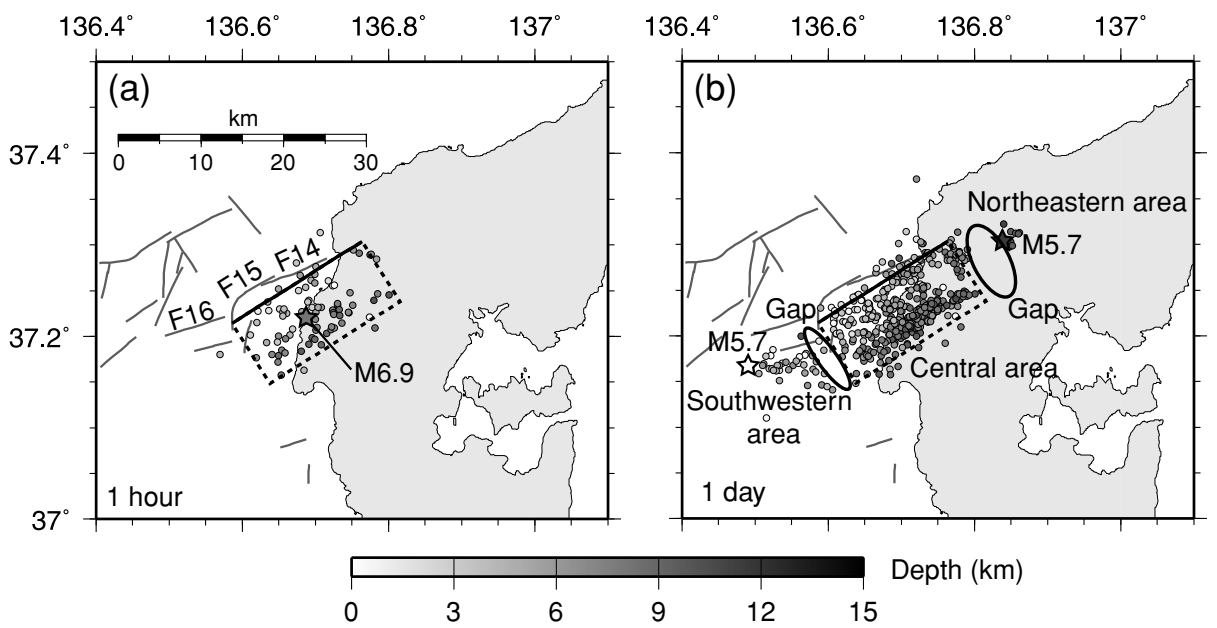

Fig. 2. A temporal variation in the distribution of the aftershocks $(M \geq 2)$ of the Noto Hanto earthquake (a) during $1 \mathrm{~h}$ and (b) during 1 day after the earthquake. The dotted rectangle with the solid line as the upper edge indicates the location of the source fault estimated in this study. Gray lines show active faults reported by Katagawa et al. (2005). Stars show the epicenters of the mainshock and the largest two aftershocks. Ellipsoids show gaps of the aftershocks.

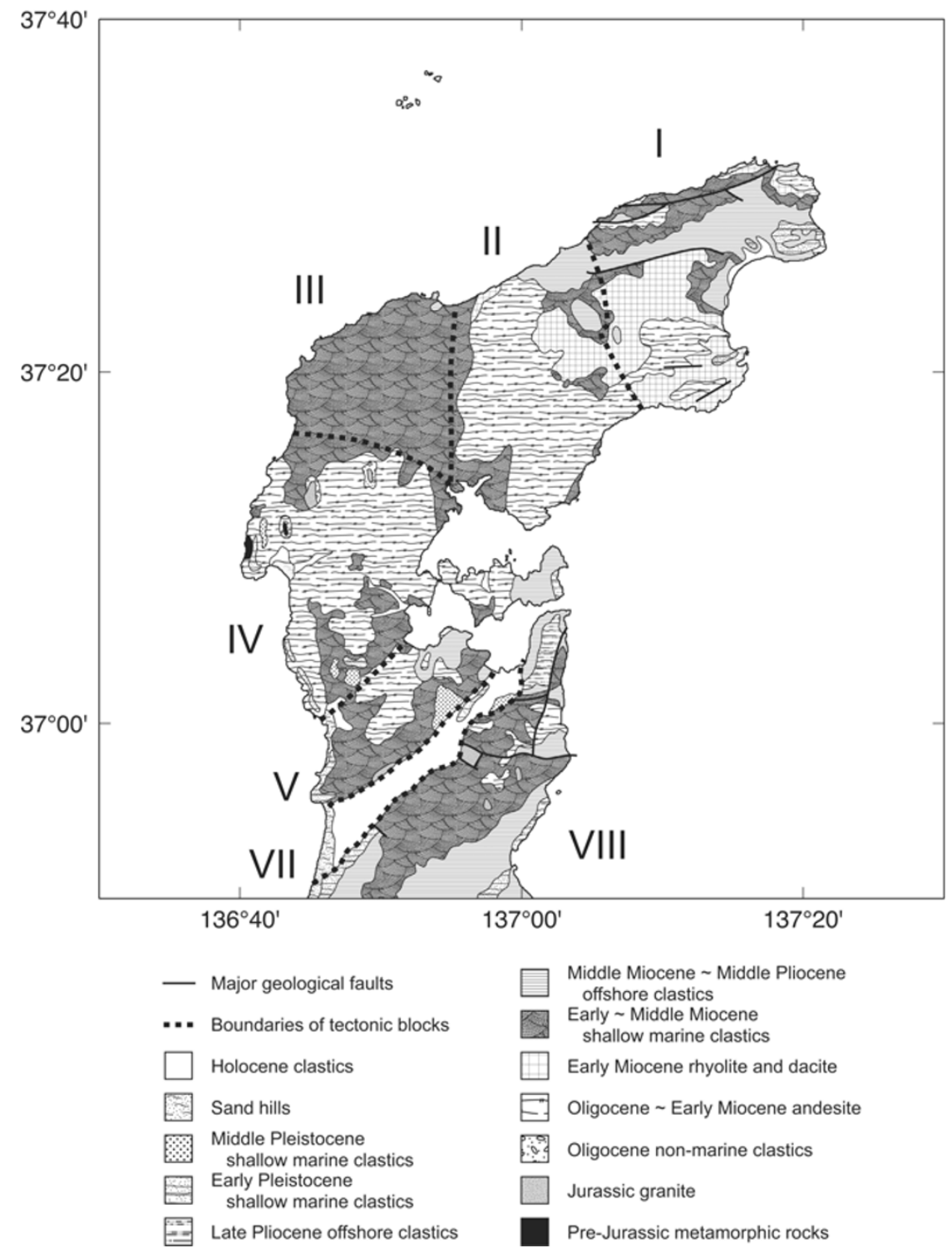

Fig. 3. Geological map of the Noto Peninsula (redrawn from Kaseno, 1993). Broken lines and Greek numbers indicate the major boundaries and numbers of each tectonic block identified by Ota and Hirakawa (1979). I: Houryu block, II: Hachibuse block, III: Saruyama block, IV: Kuwatsuka block, V: Bijyou block, VII: Ouchi depression, VIII: Sekidou block. 


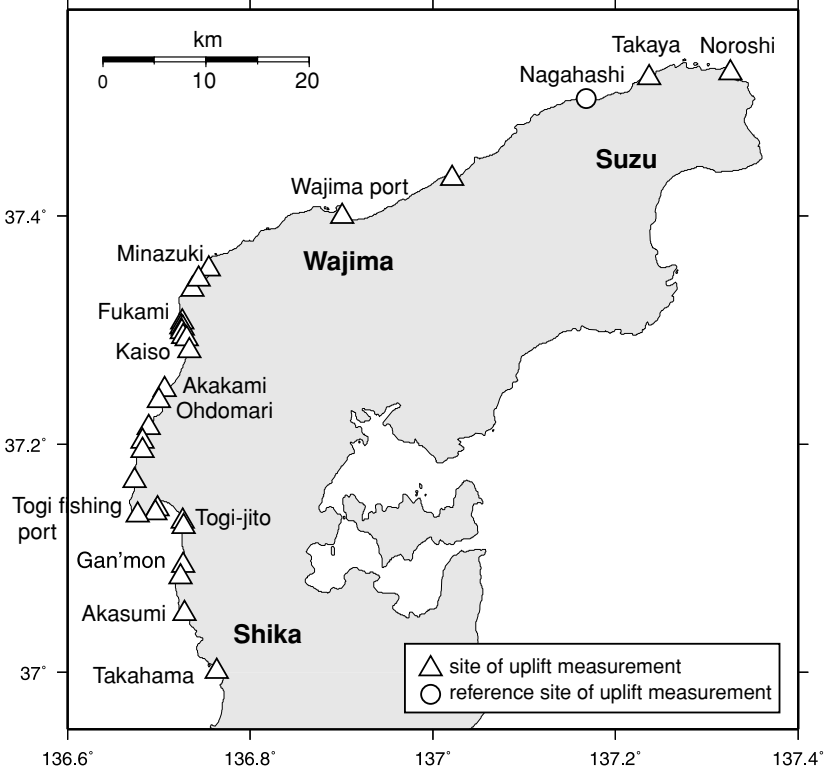

Fig. 4. Distribution of the sites of the measurements of coseismic vertical crustal deformation using the distribution of littoral organisms along the coast (triangles) of the northern Noto Peninsula. A circle shows the reference site of the tide level.

shores around Gan'mon, between Akasaki and Akakami, and between Kaiso and Fukami where there are no fishing ports. In total, four cyanobacteria, 60 oysters, 17 sea lettuces, two gulfweeds, and a stump of kelp were used to make the measurements of the coseismic vertical crustal deformation. Between two and ten colonies of each organism were analyzed at a single site. Coralline algae also show a distinctive desiccation feature, appearing as white bands on rocky shores (Plate $1(\mathrm{C})$ ). These white bands develop gradually over time (Plate $1(\mathrm{~A}-\mathrm{C})$ ).

We first measured the apparent height of the highest distribution of a colony of each organism from tide levels at the time of analysis (A, B, and C in Fig. 5(b)). This apparent height from each tide level is calibrated to a tide gauge at Nagahashi tidal station of Wajima Meteorological Observatory via observed tide levels at the station (D in Fig. 5(b), Japan Meteorological Agency, 2007). With this calibration, all records of the apparent height are virtually plotted on a tide gauge of Nagahashi tidal station. Since Tokyo Peil (T.P.), zero altitude datum of the Japanese islands, is indicated on $124.2 \mathrm{~cm}$ on the tide gauge of the Nagahashi tidal station (E in Fig. 5(b)), this height is subtracted from all records to calculate the altitude of the highest distribution of each organism.

Because the GPS station at Suzu is far from the source area, and its coseismic vertical displacement is negligibly small (GSI, 2007a), we assume that the altitude of the highest distribution of oysters at Takaya and Noroshi have been unchanged before and after the earthquake. We then subtract the average height of oysters at Takaya and Noroshi from all the heights obtained to calculate the coastal coseismic vertical displacement. Therefore, positive and negative residues after this subtraction represent the uplift and the subsidence caused by the earthquake, respectively. In addition, we employ another correction for supralittoral and infralittoral organisms. The highest distribution of supraand midlittoral organisms and that of mid- and infralittoral organisms in the Noto Peninsula show a 20 and $-30 \mathrm{~cm}$ offset, respectively (Fig. 5(a)). We therefore subtract 20
A

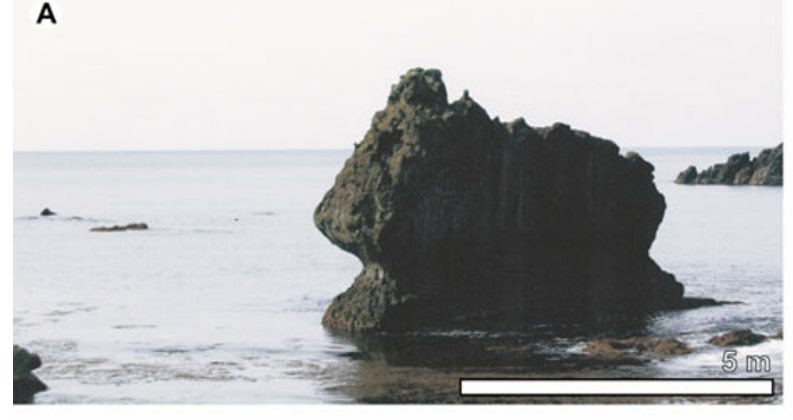

C

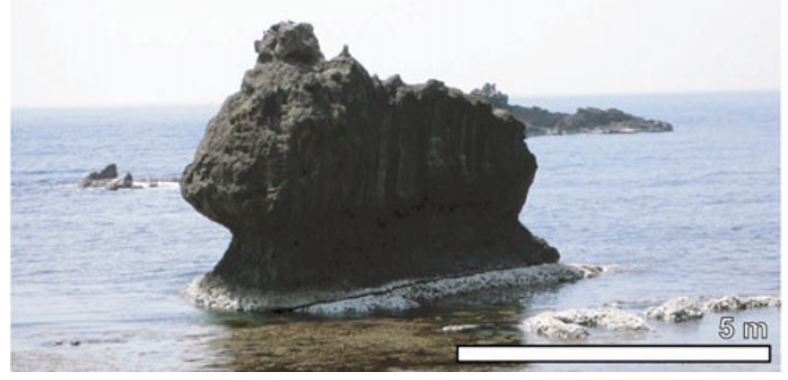

B
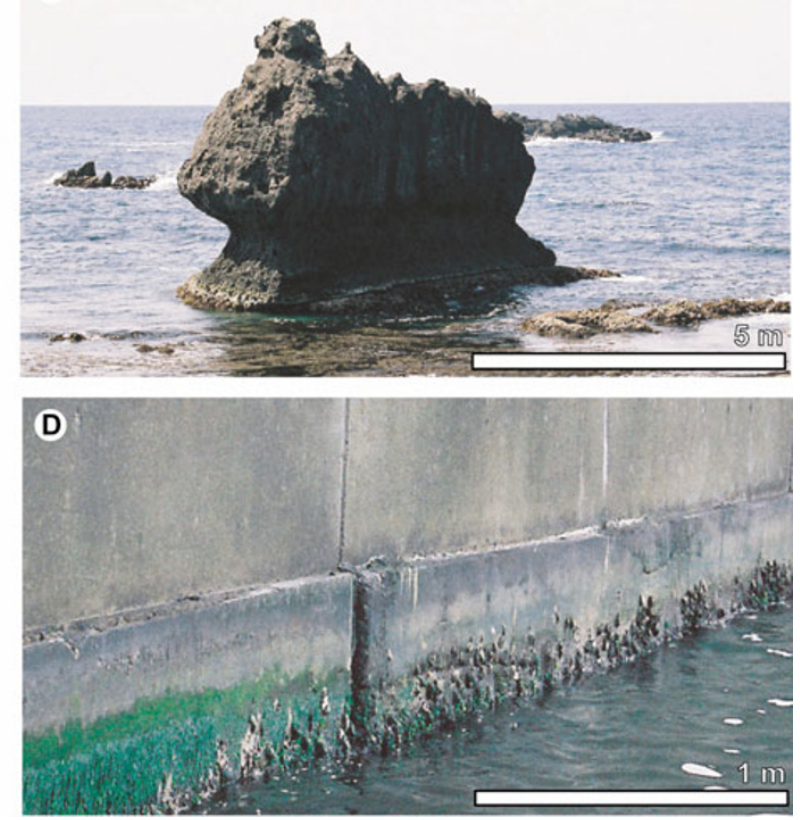

Plate 1. (A-C) Growing white bands recorded on the "Dobin-iwa (teapot stone)" and surrounding reefs at Ohdomari, and drying out ostreids and (D) sea lettuces at Togi-jito. (A) Taken on February, 2007, prior to the Noto Hanto earthquake. Note that no white bands have developed. (B) Taken on April 3, 2007, after the earthquake. Note that faint white bands have been growing. (C) Taken on April 30, 2007. White bands on the Dobin-iwa and reefs represent lithified carcasses of coralline algae. (D) Taken on April 3, 2007. Oysters and sea lettuces are attached far above the sea level at high tide 
(a)

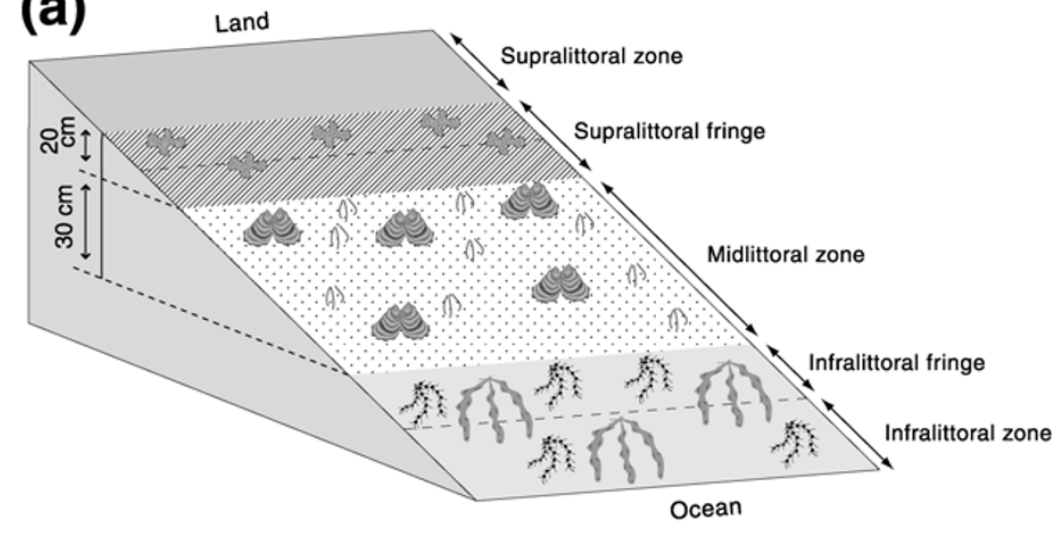

(b)

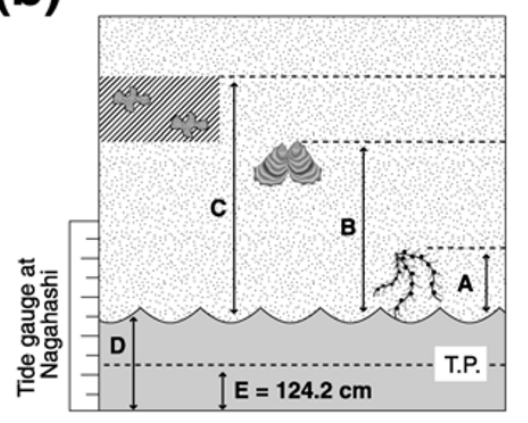

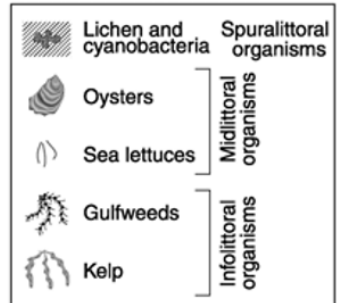

Fig. 5. Schematic views of (a) the biological vertical zonation of the littoral area in the Noto Peninsula (modified after Raffaelli and Howkins, 1996) and (b) analytical methods of this study. The offsets between the highest distribution of spuralittoral and midlittoral organisms and between midlittoral and infolittoral organisms are 20 and $30 \mathrm{~cm}$, respectively. A, B, and C in panel (b) represent relative height of the highest distributions of each organism from the sea surface at the measured time. D indicates observed tide level at Nagahashi. E is the datum level of zero altitude in the Japanese Islands (Tokyo Peil: T.P.).

$\mathrm{cm}$ from the altitude of the supralittoral organisms and add $30 \mathrm{~cm}$ to the altitude of the infralittoral organisms. The standard deviation (S.D.) and the standard error (S.E.) of the average for the repeated analyses, ten samples, in the single site (Akakami) are 3.0 and $0.9 \mathrm{~cm}$, respectively. We also calculated S.D. and S.E. for all data after eliminating outliers with Smirnov-Grubs rejection. Deviations of the measured vertical crustal deformation from the average one in a single site are calculated at each site as well. The S.D. and S.E. of all deviations are 2.9 and $0.3 \mathrm{~cm}$, respectively. Although Awata et al. (2008) used the Wajima tidal station, the strong ground motion may affect the sea bank where we performed the measurements at Wajima. We therefore prefer to choose Nagahashi as the reference site. Examination of the effect of the difference in the reference site proves that the estimated coseismic vertical displacement is little affected by the selection of the reference site. In fact, the average of all differences between vertical crustal deformations in each site calibrated against Nagahashi and Wajima agrees statistically.

2.1.2 Coseismic crustal deformation detected from littoral organisms Figure 6 shows the obtained coseismic vertical displacement along the coast of the northern and western Noto Peninsula. The highest uplift of $44 \mathrm{~cm}$ is observed at Akakami, the middle part of the measured area. The subsidence at the southernmost site of Takahama is $3 \mathrm{~cm}$ and the uplifts at northern sites of Minazuki and beyond are almost $0 \mathrm{~cm}$. These data indicate that the coseis- mic vertical crustal deformation along the coast is practically restricted between Akasumi and Minazuki. The uplift height at Togi fishing port is $20 \mathrm{~cm}$, and successive gradual uplift is found between Akasumi and Akakami. On the other hand, north from Akakami, the uplift height suddenly decreases in the vicinity of Kaiso and becomes negative at Fukami. A gradual decrease in subsidence is observed between Fukami and Minazuki. These lines of observations indicate that the coseismic vertical crustal deformation of asymmetric anticlinal pattern has the largest uplift and subsidence at Akakami and Fukami, respectively.

2.1.3 Comparison with other indices About 4.5 months after the earthquake, leveling results along the western part of the Noto Peninsula, between Wajima and Shika, were published by GSI (GSI, 2007b). Though three quarter of their route unfortunately runs in inland areas, the leveling data of one of the most important interval between Kaiso and Sekinohana are obtained along the coastline. In Fig. 6, we compare the leveling data with our results. Note that we need to add $2.5 \mathrm{~cm}$ to the leveling data to compare the absolute values because the reference point of the leveling data is Wajima port. The leveling data clearly indicate asymmetrical dome-like crustal deformation between Kaiso and Togi and show a good consistency with our results (Fig. 6). In addition to these measurements, InSAR analyses have been performed (Fukushima et al., 2008; Ozawa et al., 2008). Those results indicate that the highest vertical uplift of $35 \sim 40 \mathrm{~cm}$ is observed at around Akakami and the 


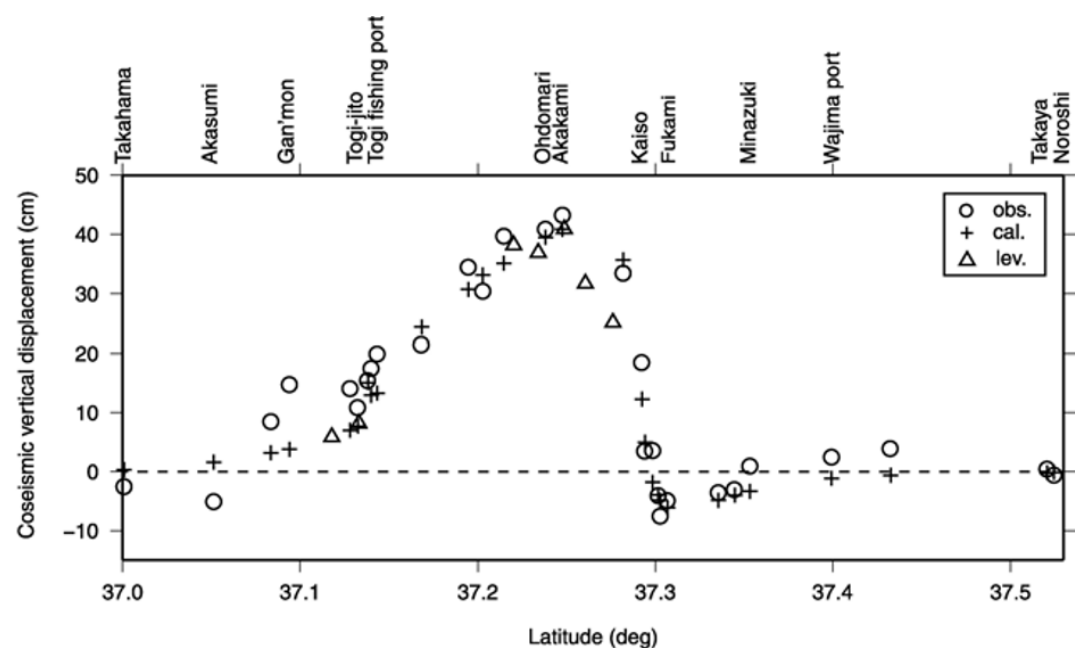

Fig. 6. Observed (circles) and calculated (crosses) coseismic vertical crustal deformation along the coast of the northern Noto Peninsula for measurement sites of the distribution of littoral organisms. Triangles show the leveling data along the coast reported by GSI (2007b). Note that there is a difference of $2.5 \mathrm{~cm}$ between our observations and the leveling data because of differences at the reference sites.
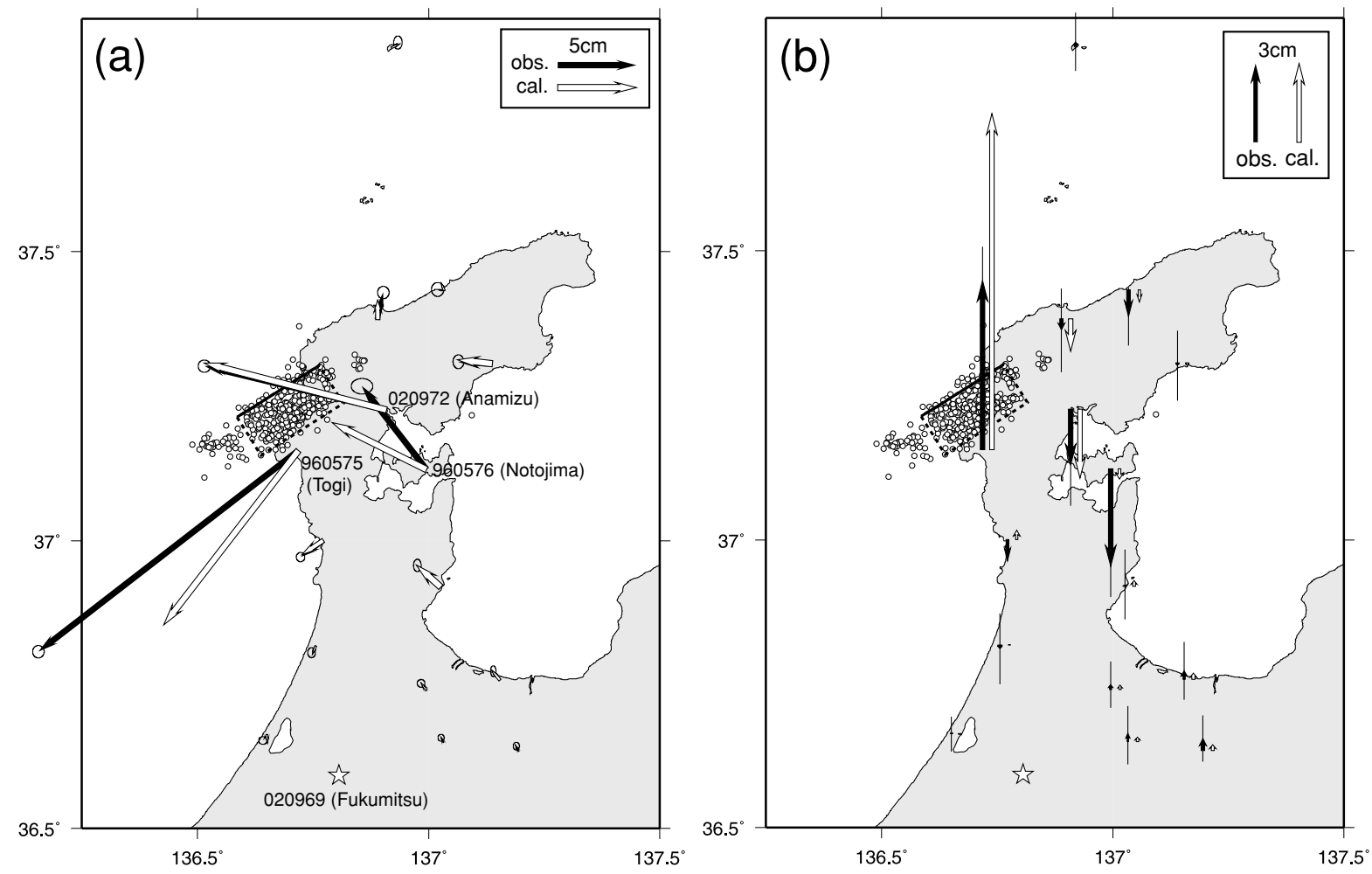

Fig. 7. (a) Observed and calculated horizontal displacements for GPS stations. A star shows the reference station. $2 \sigma$ error ellipses are attached to the observed displacement. Circles are aftershocks within 1 day after the mainshock reported by JMA. The dotted rectangle with the solid line as the upper edge indicates the location of the source fault estimated in this study. (b) Observed and calculated vertical displacements for GPS stations. $2 \sigma$ error bars are attached to the observed displacement. All other symbols are the same as those of Fig. 7(a).

uplift decreases gradually southward. Although this uplift pattern is consistent with our results, the value of the highest uplift is slightly smaller than those of this study and the leveling data.

\subsection{GPS}

All GPS stations used in this study are a part of the Japanese nationwide GPS network (GEONET) maintained by GSI. We selected 16 GPS stations in and around the Noto Peninsula to obtain the coseismic displacement. GPS data provide not only information on vertical crustal defor- mation but also good quality information on the horizontal component in a wide area, as shown in Figs. 7(a) and 7(b). The coseismic displacements are calculated using the final (F2) solution of the GEONET from the differences between the weekly average just before (March 18-24) and after (March 26-April 1) the earthquake. The plotted displacement is relative to the site 020969 (Fukumitsu), which is at a distance of about $60 \mathrm{~km}$ from the source area and is considered to record no significant crustal movement due to the earthquake. For the sites of 960575 (Togi) and 960576 (No- 
Table 1. Fault parameters estimated from the coseismic deformation by the distribution of midlittoral and infralittoral organisms and GPS.

\begin{tabular}{ccccccccr}
\hline $\begin{array}{c}\text { Latitude } \\
\left({ }^{\circ}\right)\end{array}$ & $\begin{array}{c}\text { Longitude } \\
\left({ }^{\circ}\right)\end{array}$ & $\begin{array}{c}\text { Depth } \\
(\mathrm{km})\end{array}$ & $\begin{array}{c}\text { Length } \\
(\mathrm{km})\end{array}$ & $\begin{array}{c}\text { Width } \\
(\mathrm{km})\end{array}$ & $\begin{array}{c}\text { Strike } \\
\left({ }^{\circ}\right)\end{array}$ & $\begin{array}{c}\text { Dip } \\
\left({ }^{\circ}\right)\end{array}$ & $\begin{array}{c}\text { Rake } \\
\left({ }^{\circ}\right)\end{array}$ & $\begin{array}{c}\text { Slip } \\
(\mathrm{m})\end{array}$ \\
\hline 37.214 & 136.586 & 1.5 & 18.6 & 14.5 & 58 & 53 & 139 & 1.3 \\
\pm 0.007 & \pm 0.006 & \pm 0.2 & \pm 1.3 & \pm 0.8 & \pm 1 & \pm 1 & \pm 2 & \pm 0.1 \\
\hline
\end{tabular}

tojima), the strong ground motion caused displacements of about $3 \mathrm{~cm}$ due to the tilt of GPS pillars (Tobita et al., 2007). This effect is corrected for the estimation of the coseismic displacement although there remain some uncertainties on the values at Togi and Notojima. The data of GPS shown in Fig. 7 are those after the correction of the monument tilting.

Large horizontal coseismic displacements are observed near the source area: $20.9 \mathrm{~cm}$ towards the WSW at Togi, $11.9 \mathrm{~cm}$ towards the WNW at 020972 (Anamizu), and $6.7 \mathrm{~cm}$ towards the NW at Notojima, while the displacement is $3.3 \sim 7.2 \mathrm{~mm}$ at stations that are $50 \mathrm{~km}$ away from the epicenter (Fig. 7(a)). A similar spatial variation is observed for the vertical coseismic displacements: $6.4 \mathrm{~cm}$ at Togi, $-2.1 \mathrm{~cm}$ at Anamizu, and $-3.7 \mathrm{~cm}$ at Notojima, while it is $-1.4 \sim 4.6 \mathrm{~mm}$ for stations far away (Fig. 7(b)).

\section{Inversion Method}

We use the non-linear inversion method by Matsu'ura and Hasegawa (1987) to estimate the parameters of a single rectangular fault with uniform slip in elastic half-space. We assume homogeneous elastic half-space to calculate displacements due to a rectangular fault (Okada, 1992). From the distribution of the aftershocks (Fig. 1), we use the fault parameters of the nodal plane dipping down to southeast, and the moment tensor solution estimated by Takeda et al. (2007) as the initial values of the inversion. We also use the location and the size of the fault estimated by Tobita $e t$ al. (2007) from the analysis of continuous GPS data as the initial values.

For the GPS data, the standard deviations of daily relative coordinates for each component are assigned as data uncertainties. We adopt $3 \mathrm{~cm}$ for the vertical components and $1.5 \mathrm{~cm}$ for the horizontal components as the uncertainties for the stations of Togi and Notojima with the tilted pillar. For the coseismic vertical displacement estimated by the distribution of littoral organisms, it is likely that the uncertainties are larger than those of the GPS data. Taking into account the error mentioned before $(2 \sigma=5.8 \mathrm{~cm})$, we provide $\sim 6 \mathrm{~cm}$ as the maximum uncertainties for the coseismic vertical displacement from the distribution of the organisms in the inversion.

\section{Results of the Estimation of the Source Fault}

The estimated fault parameters and errors are listed in Table 1, and the location of the source fault is shown in Fig. 1. The strike of $58^{\circ}$ and the dip of $53^{\circ}$ of the fault are consistent with the aftershock distribution. The fault slip is $1.3 \mathrm{~m}$ of a reverse fault type with a right-lateral slip that is consistent with the source mechanisms estimated from seismic data. The seismic moment of the earthquake is $1.0 \times 10^{19} \mathrm{~N} \mathrm{~m}\left(M_{\mathrm{W}} 6.6\right)$ using a rigidity of $30 \mathrm{GPa}$. This value is consistent with that of moment tensor solutions estimated from long-period seismic waves (Hoshiba, 2007; Takeda et al., 2007) and other geodetic and seismological estimates (e.g. Horikawa, 2008; Ozawa et al., 2008).

The length of the fault, $18.6 \mathrm{~km}$ along the strike, is slightly shorter than that estimated by the inversion of the GPS data with fixed fault dip and strike based on the aftershock distribution (Tobita et al., 2007; Ozawa et al., 2008) and slightly longer than that estimated by the coastal vertical crustal deformation with a fixed fault dimension based on the aftershock distribution (Awata et al., 2008). There is, however, a possibility that the southwestern edge of the fault model is determined artificially because of the limited observation of the coseismic crustal deformation data on land. We apply fixed fault length models, 15 25 km along the strike, to check the reliability of the location and the size of the source fault. Figure 8(a) shows the Akaike Information Criteria (AIC) of the estimated fault model for a fixed fault length. We can find no statistically significant difference among the models with the fault length of 16 $21 \mathrm{~km}$. Figure 8(b) shows the location of the fault models of $16 \mathrm{~km}$ and $21 \mathrm{~km}$ length, respectively. This range is consistent with the fault lengths obtained by Tobita et al. (2007) and Awata et al. (2008). It is important to note that the $21 \mathrm{~km}$ fault length model also lies on the central aftershock area and does not extend to the southwestern aftershock area. Of course, there is also a possibility that this evaluation depends on the uncertainties we provide. Estimated fault models, however, never extend beyond the half of the southwestern aftershock area, even if we change uncertainties within the acceptable but extreme range.

The depth of the upper edge of the fault is $1.5 \mathrm{~km}$, and most of the shallow part of the fault lies beneath the sea area. These are the reasons why no clear surface source faults are found for the Noto Hanto earthquake.

We compare the calculated coseismic vertical displacement along the coast with the observed one as a function of the latitude of the measurement sites in Fig. 6. This shows a good fit of the calculations to the observations, indicating that the fault model estimated here adequately represents the fault geometry and the slip. A somewhat large misfit of $11 \mathrm{~cm}$ is, however, found at Gan'mon. We cannot fit these data reasonably although we tried to apply various fault parameters and uncertainties. Because the Gan'mon site represents a rocky shore rather than a fishing port and is completely open to the ocean, the splash and swell of the ocean could make a measurement error larger than that of the other sites. A heterogeneous fault slip model cannot explain the data at Gan'mon as well (Horikawa, personal communication).

In Figs. 7(a) and 7(b), we compare the calculated horizontal and vertical displacements with the observed ones by GPS, respectively. Both figures also show that our fault 
(a)

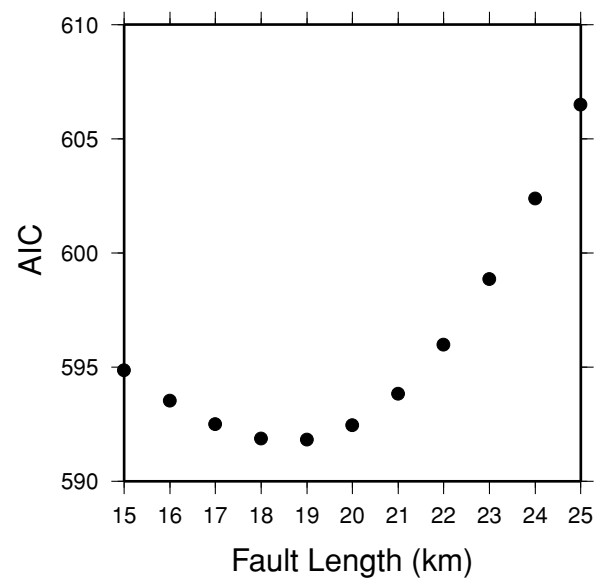

(b)
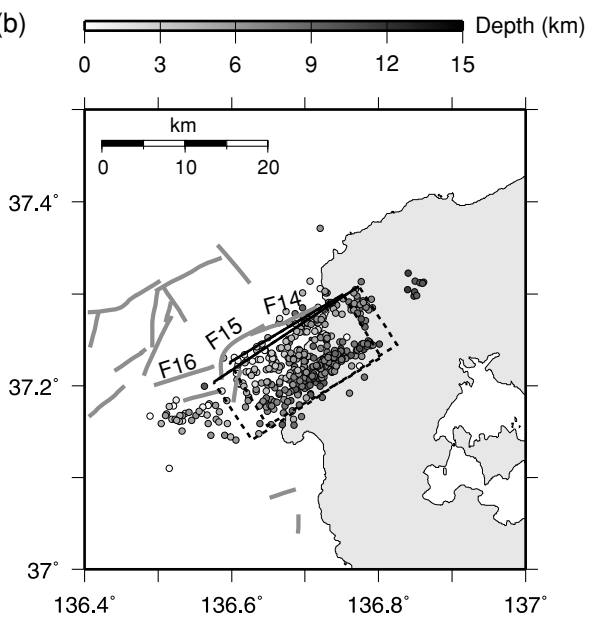

Fig. 8. (a) A plot of the fixed fault length versus the value of Akaike Information Criteria (AIC). (b) The location of the fault models (dotted rectangles with solid line as the upper edge) whose fault lengths are $16 \mathrm{~km}$ and $21 \mathrm{~km}$, respectively. Gray lines are active faults reported by Katagawa et al. (2005). Circles are aftershocks $(M \geq 2)$ that occurred during 1 day after the mainshock reported by JMA.

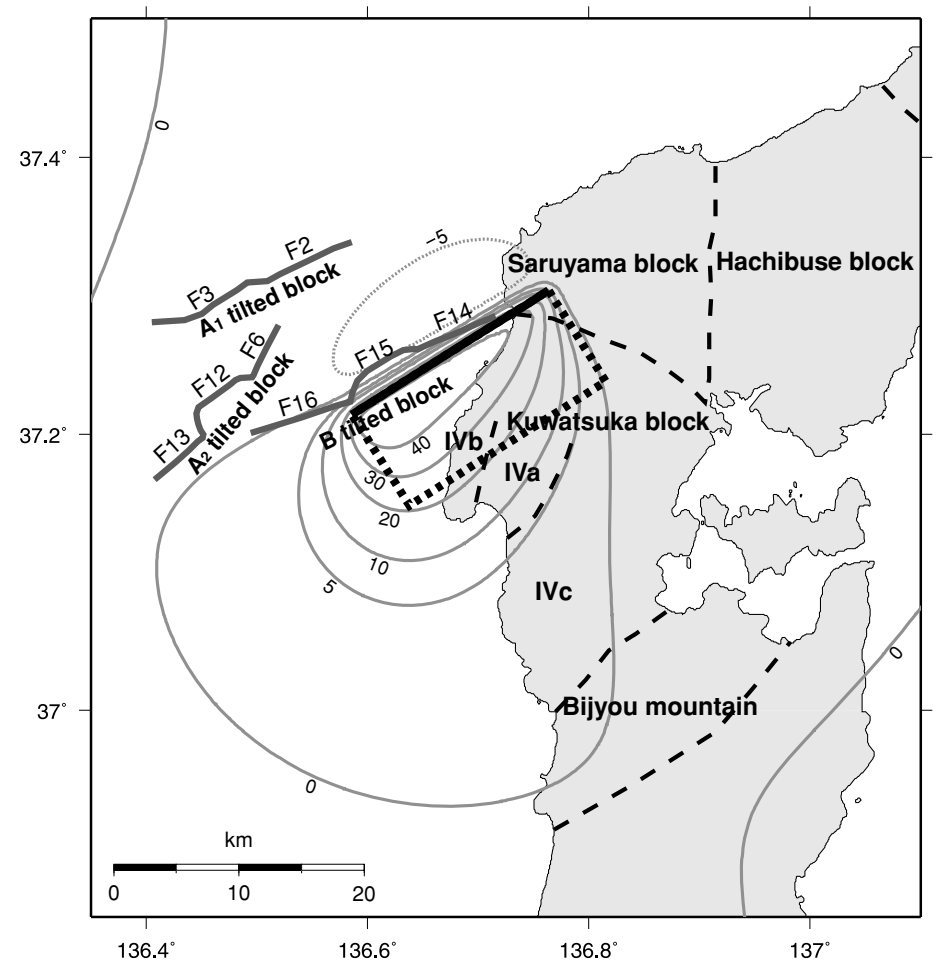

Fig. 9. Distribution of coseismic vertical displacements calculated by the fault model estimated in this study in centimeter (light gray solid lines for positive and a dotted line for negative), tilted blocks, and relating active faults as the boundaries (dark gray lines) reported by Katagawa et al. (2005), and block structures around the source area reported by Ota and Hirakawa (1979). Broken lines are boundaries between the blocks. The dotted rectangle with the solid line as the upper edge indicates the location of the source fault estimated in this study.

model explains the observed deformation well, except for the stations with the tilted monument at Togi and Notojima. The result of Tobita et al. (2007) also showed large misfits at these two stations. Figure 9 shows the pattern of the vertical displacement calculated by the fault model estimated in this study. This pattern is consistent with a concentric crustal deformation pattern obtained by ALOS/PALSAR data (Japan Aerospace Exploration Agency, 2007; Tobita et al., 2007).

\section{Discussion}

\subsection{Segmentation of faults and block structures around the source area}

We discuss the relationships among the fault model estimated in this study and the distribution of the aftershocks, active faults, and geological structures around the source area. As mentioned in Introduction, the aftershock area can be divided into three sub-areas, the southwestern, the central and the northeastern areas. The estimated source fault is located in the central aftershock area (Fig. 2(b)). The 
largest aftershocks $\left(M_{\mathrm{JMA}} 5.3\right)$ occurred in the northeastern area at 18:11 (JST), March 25, 2007 and at the southwestern end in the southwestern area at 7:16 (JST) March 26, 2007 (Fig. 2(b)). CMT solutions of the largest aftershock on March 25 are dominant on the thrust component and seem to differ a little from that of the mainshock: a lack of the right lateral component and slight differences of the strike and the dips of the nodal planes (Hoshiba, 2007 (JMA); Takeda et al., 2007 (F-net)). The location of the source fault estimated here, together with the gap of the aftershocks, suggests that the northeastern area forms a different fault plane from the area ruptured during the mainshock. Alternatively, the northeastern area may comprise another segment, even if the central and the northeastern areas share a single fault plane. On the other hand, CMT solutions of the largest aftershock on March 26 in the southwestern area show a strike-slip mechanism that is different from that of the mainshock (Hoshiba, 2007; Takeda et al., 2007). This suggests that a fault plane of this event is different from that of the mainshock. A narrow gap of the aftershocks exists between the central and the southwestern areas (Fig. 2(b)). This gap corresponds to the southwestern edge of our fault model. Furthermore, the strike of the active fault, F15, curves in this gap and beyond this gap another active fault, F16, extends (Katagawa et al., 2005). A curvature of the active fault on the gap can be seen for the active fault by GSJ (2007a). We therefore consider that the southwestern area may be a different fault plane from that caused the mainshock, or a different segment if F14, F15, and F16 consist of a single fault zone, as indicated by GSJ (2007a).

F14, F15, and F16 of Katagawa et al. (2005) and the northeastern part of the active fault of GSJ (2007a) are located at the northwestern edge of the distribution of the aftershocks on the seafloor. These faults are high-angle reverse faults dipping down to southeast that are consistent with the distribution of the aftershocks, suggesting that the source fault corresponds to those deeper extensions. From our model, the source fault corresponds to F14 and F15 and the northeastern part of the active fault of GSJ (2007a) beneath the seafloor. F16 seems to be related to the southwestern area of the aftershocks and independent of the rupture of the mainshock, or to cause no dominant slip even if the source fault includes F16. Our fault model also shows that the source fault extends slightly beneath the land area where there are no on land active faults related to the source fault, as shown in Fig. 1.

There have been several studies to estimate heterogeneous fault slip of the Noto Hanto earthquake geodetically (Fukushima et al., 2008; Ozawa et al., 2008), and sesimologically (Horikawa, 2008), and both (Asano and Iwata, 2007). For example, Horikawa (2008) obtained a similar result from the analysis of the rupture process of the Noto Hanto earthquake using strong motion data. He used the fault plane that covered the central aftershock area only for the inversion analysis and reproduced well the observed waveforms, supporting the premise that the rupture of the mainshock is restricted in the central area. These studies clearly showed that the Noto Hanto earthquake was characterized by a dominant slip area just above the hypocenter and that the area was located in the central aftershock area. This is the reason why the observed crustal deformation can be reproduced by our simple model, a rectangle fault with uniform slip.

Namegaya and Satake (2008) discussed the dimension and the location of the source fault and the amount of the slip in terms of tsunami waveforms. They compared the observed tsunami waveforms with synthetic ones calculated by the source models of Tobita et al. (2007), Awata et al. (2008), and Horikawa (2008) and concluded that the tsunami source area was slightly smaller than, and the slip amount slightly larger than the model of Awata et al. (2008). This supports the proposal that the western edge of the source fault does not extend to the southwestern aftershock area.

The distribution of marine terraces indicates cumulative uplift with southward tilting, including a small component of eastward tilting, of the whole Noto Peninsula and several block structures with southward tilting (Ota et al., 1976; Ota and Hirakawa, 1979). There are two geological block structures around the aftershock area on land, the Kuwatsuka and the Saruyama blocks (Fig. 9). These block structures are also recognized by a detailed Bouguer anomaly map (Honda et al., 2008). The central aftershock area lies approximately in the Kuwatsuka block and the northeastern area in the Saruyama block. Following the relationship between the location of the fault model and the aftershock distribution, we consider that the rupture of the mainshock on land is mainly restricted to the Kuwatsuka block, especially the northwestern part, sub-blocks IVb and IVa of Ota and Hirakawa (1979).

\subsection{Crustal deformation since the Pleistocene}

The western offing of the Noto Peninsula has experienced regional tectonic deformation (Katagawa et al., 2005). Katagawa et al. (2005) identified two geological block structures of A (A1 and A2) and B (Fig. 9). These blocks show southeastward tilting and their northwestern edges are bounded by active faults, F14 and F15, which correspond to the source fault of the Noto Hanto earthquake, together with F16, form the northwestern boundary of the $\mathrm{B}$ tilted block. The geological profiles indicate the relative uplift of the hanging wall side of F14, F15, and F16, the B tilted block, and the relative subsidence of the footwall side of those to the A tilted block (Katagawa et al., 2005). Furthermore, in the B tilted block, the F14 and F15 blocks show the uplift relative to F16 block. The B tilted block corresponds to the Kuwatsuka block in terms of geological structure (Katagawa et al., 2005). We therefore presume that the movement of the F14 and F15 blocks in the B tilted block controls the structure of the northwestern part of the Kuwatsuka block. If this is the case, the height distribution of the marine terrace of M1 (Ota and Hirakawa, 1979), whose age is estimated to be $120 \mathrm{ka}$ using the uranium-series radioisotopes (Omura, 1980), is expected to correlate with the coseismic vertical crustal deformation in the IVb and IVa sub-blocks. We compare the observed coseismic vertical displacement with the height of the M1 between Togi-jito and Akakami in Fig. 10. Both the uplift and the height of the M1 show the same trend, the highest at the northernmost and a gradual decrease towards the southern end. In 


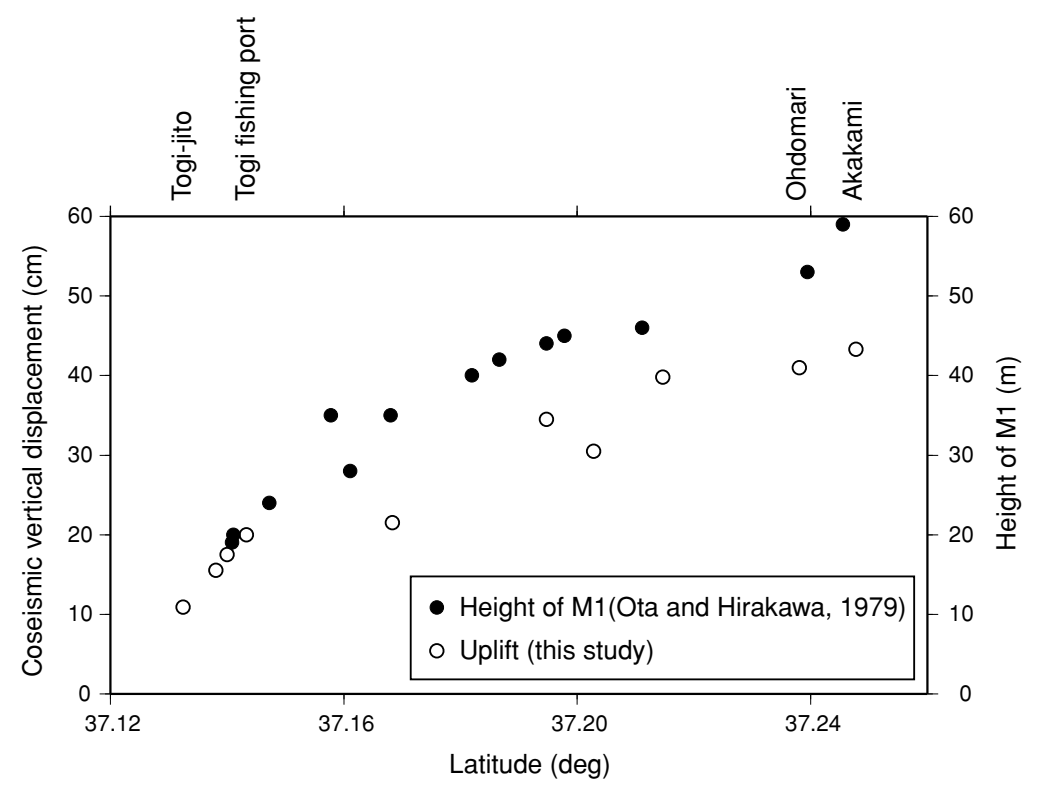

Fig. 10. Comparison of the observed coseismic vertical displacement in this study (open circles) in $\mathrm{cm}$ with the height of the marine terrace of M1 reported by Ota and Hirakawa (1979) (solid circles) in m plotted as a function of the latitude of the sites.

the Saruyama block, M1 has not been identified because of its Rias-like coastline (Ota and Hirakawa, 1979). In addition, the detailed Bouguer anomaly map indicates that the basement depth of the northwestern part of the Kuwatsuka block is shallower than that of the southwestern part of the Saruyama block (Honda et al., 2008). These features mentioned above do not contradict the observed coseismic vertical displacement along the coast (Fig. 6) and the calculated vertical crustal deformation from the fault model (Fig. 9).

GSJ (2007b) made a high-resolution multi-channel acoustic exploration in and around the source area of the earthquake. They recognized an active fault that corresponded to the F14, F15, and F16 of Katagawa et al. (2005), and identified a few dozens $\mathrm{cm}$ of deformation on a seafloor. To estimate an interval of each rupture of the fault, they compared this reflection profile to an older one obtained in 1988. They discovered that the erosion surface at the last glacial stage $(\sim 20 \mathrm{ka})$ have already been deformed in the 1988 profile, though strata younger than $\sim 20$ ka have not. Consequently, GSJ (2007b) concluded that this active fault could rupture once or twice in $20 \mathrm{kyr}$.

Based on this assumption and the uplift height of about $40 \mathrm{~cm}$ on the ground surface per one fault movement, $2.4 \sim 4.8 \mathrm{~m}$ uplift is expected in these $120 \mathrm{kyr}$. On the other hand, among the active faults detected around the source area, only F14 and F15 are estimated as the source fault of the Noto Hanto earthquake in this study. Considering that these two segments produced about $40 \mathrm{~cm}$ uplift at the surface, it can be expected that the total fault movement of these three segments would produce $\sim 1 \mathrm{~m}$ uplift at the surface. In this case, a $12 \mathrm{~m}$ uplift at most should be expected with these fault activities in these $120 \mathrm{kyr}$.

Compared to the $\sim 40 \mathrm{~m}$ block movement observed in the altitudinal distribution of the M1 marine terrace (Fig. 10), a $12 \mathrm{~m}$ uplift in maximum with the fault activity is far too small to explain the total tilt of this block for these $120 \mathrm{kyr}$. We therefore infer that at least some parts of this tilting
( $\sim 12 \mathrm{~m}$ in maximum) can be attributed to the local fault movements, and the rest of the tilting have been produced with the diastrophism of the Noto Peninsula.

In this context, the geological map of the Noto Peninsula illustrates an interesting pattern of distribution of each lithofacies (Fig. 3). The distributions of the Oligocene $~$ Early Miocene andesite and Early Middle Miocene shallow marine clastics, in particular, show a good correspondence with the distribution of the tectonic blocks (Fig. 3). This analogous distribution and the crustal deformation history of the Noto Peninsula imply that the present-day geological structures of the Noto Peninsula are closely related with the block movement.

\section{Conclusions}

We construct a fault model of the 2007 Noto Hanto earthquake from the coseismic crustal movement measured by the distribution of littoral organisms from the sea level and continuous GPS observation. Assuming a rectangular fault with a uniform slip in elastic half-space, we obtain the fault model of a reverse fault with a right-lateral slip of $1.3 \mathrm{~m}$ on a $18.6 \mathrm{~km} \times 14.5 \mathrm{~km}$ area. The seismic moment is $1.0 \times 10^{19} \mathrm{~N} \mathrm{~m}\left(M_{\mathrm{W}} 6.6\right)$ using the rigidity of $30 \mathrm{GPa}$. This value of seismic moment is consistent with those estimated by seismological analyses. The geometry of the fault model is also consistent with the strike and the dip of the aftershock distribution. Comparison of the fault model with the distribution of the aftershocks, active faults, and geological structures suggests that the source size of the Noto Hanto earthquake is controlled by the geological structures around the source area. The observed coseismic uplift and the reflection profile in the source area indicate that the origin of the crustal deformation of the northwestern Noto Peninsula since the Pleistocene can be divided into two independent tectonic activities. The first one is obviously the active fault movement, such as the 2007 Noto Hanto earthquake, and the other one can be the background diastrophism. These 
two types of tectonics play an important role for the evolution of the Noto Peninsula.

Acknowledgments. We are grateful to Keiichi Yamamoto and Akira Ishiwatari who informed us of the uplift of the coast. Masayoshi Nakanoya provided us with the photo of the Dobiniwa prior to the earthquake. Discussion with Haruo Horikawa was valuable. Ikuro Sumita read the manuscript carefully. Comments of anonymous reviewers were useful to improve the manuscript. The hypocentral catalogue and the tide gauge record provided by the Japan Meteorological Agency are used. Most of figures are drawn by GMT software (Wessel and Smith, 1998).

\section{References}

Asano, K. and T. Iwata, Source rupture process of the 2007 Noto Hanto earthquake estimated from strong motion data and GPS data, Seismological Society of Japan, 2007 Fall Meeting, A21-04, 2007 (in Japanese).

Awata, Y., S. Toda, H. Kaneda, T. Azuma, H. Horikawa, M. Shishikura, and T. Echigo, Coastal deformation associated with the 2007 Noto Hanto earthquake, central Japan, determined by uplifted and subsided intertidal organisms, Earth Planets Space, 2008 (in press).

Bodin, P. and T. Klinger, Coastal uplift and mortality of intertidal organisms caused by the September 1985 Mexico Earthquakes, Science, 233, 1071-1073, 1986.

Carver, G. A., A. S. Jayko, D. W. Valentine, and W. H. Li, Coastal uplift associated with the 1992 Cape Mendocino earthquake, northern California, Geology, 22, 195-198, 1994.

Fukushima, Y., T. Ozawa, and M. Hashimoto, Fault model of the 2007 Noto Hanto earthquake estimated from PALSAR radar interferometry and GPS data, Earth Planets Space, 60, 99-104, 2008.

Geographical Survey Institute, Continuous GPS observation around the Noto Peninsula (the final results), http://www.gsi.go.jp/ BOUSAI/isikawa/tikaku.htm, 2007a.

Geographical Survey Institute, Leveling results after the Noto Hanto earthquake in 2007, http://www.gsi.go.jp/WNEW/PRESSRELEASE/2007/0711.htm, 2007b (in Japanese).

Geological Survey of Japan, Advanced Industrial Science and Technology, Seamless digital geological map of Japan (1:200,000), 2005.

Geological Survey of Japan, Advanced Industrial Science and Technology, Geology of the Noto Peninsula, http://www.gsj.jp/ jishin/noto/noto1.html, 2007a (in Japanese).

Geological Survey of Japan, Advanced Industrial Science and Technology, Observation of an active fault of $18 \mathrm{~km}$ length at the source area of the Noto Hanto earthquake, http://www.aist.go.jp/ aist_j/press_release/pr2007/pr20070730/pr20070730.html, 2007b (in Japanese).

Honda, R., Y. Hiramatsu, Y. Kono, and H. Katagawa, Gravity anomalies and the geologic block structures in and around the aftershock area of the 2007 Noto Hanto Earthquake, Earth Planets Space, 60, 111-115, 2008.

Horikawa, H., Characterization of the 2007 Noto Hanto, Japan, Earthquake, Earth Planets Space, 2008 (in press).

Hoshiba, M., Outline of the Noto Hanto Earthquake in 2007, Japan Geoscience Union Meeting 2007, Z255-P001, 2007.

Japan Aerospace Exploration Agency, Observation results of the 2007 Noto Peninsular Earthquake by the advanced land observing satellite "Daichi", http://www.jaxa.jp/press/2007/04/20070412_daichi_e.html, 2007.

Japan Meteorological Agency, Observed tide at Noto, http://www.data. kishou.go.jp/kaiyou/db/tide/dbindex.html, 2007 (in Japanese).

Kaseno, Y., Geology of Ishikawa-ken, Japan (with Geological Maps), 321 pp, Ishikawa Pref. and Hokuriku Geology Institute, 1993 (in Japanese).
Katagawa, H., M. Hamada, S. Yoshida, H. Kadosawa, A. Mitsuhashi, Y. Kono, and Y. Kinugasa, Geological development of the west sea area of the Noto Peninsula district in the Neogene Tertiary to Quaternary, central Japan, J. Geogr., 114, 791-810, 2005 (in Japanese with English abstract).

Kato, M., Tertiary volcanic and sedimentary rocks in Noto Peninsula, Ishikawa Prefecture, The 108th annual meeting of the Geological Society of Japan, excursion guidebook, 45-60, 2001 (in Japanese).

Matsu'ura, M. and Y. Hasegawa, A maximum likelihood approach to nonlinear inversion under constraints, Phys. Earth Planet. Inter., 47, 179187, 1987.

Namegaya, Y. and K. Satake, Tsunami generated by the 2007 Noto Hanto earthquake, Earth Planets Space, 60, 127-132, 2008.

Okada, Y., Internal deformation due to shear and tensile faults in a halfspace, Bull. Seismol. Soc. Am., 82, 1018-1040, 1992.

Omura, A., Uranium-series age of the Hiradoko and Uji shell beds, Noto Peninsula, central Japan, Trans. Proc. Paleont. Soc. Jpn., N.S., 117, $247-$ 253, 1980.

Ortlieb, L., S. Barrientos, and N. Guzman, Coseismic coastal uplift and corraline algae record in northern Chile: The 1995 Antofagasta earthquake case, Quat. Sci. Rev., 15, 949-960, 1996.

Ota, Y. and K. Hirakawa, Marine terraces and their deformation in Noto Peninsula, Japan Sea side of central Japan, Geogr. Rev. Jpn., 52, 169189, 1979 (in Japanese with English abstract).

Ota, Y., T. Matsuda, and K. Hirakawa, Active faults in Noto Peninsula, Central Japan, Quat. Res., 15, 109-128, 1976 (in Japanese with English abstract).

Ozawa, S., H. Yarai, M. Tobita, H. Une, and T. Nishimura, Crustal deformation associated with the Noto Hanto Earthquake in 2007 in Japan, Earth Planets Space, 60, 95-98, 2008.

Raffaelli, D. and S. Hawkins, Intertidal Ecology, 356 pp., Chapman \& Hall, London, 1996.

Rajendran, C. P., K. Rajendran, R. Anu, A. Earnest, T. Machado, P. M. Mohan, and J. Freymueller, Crustal deformation and seismic history associated with the 2004 Indian Ocean earthquake: A perspective from the Andaman-Nicobar Islands, Bull. Sediment. Soc. Am., 97, S174S191, 2007.

Research Group for Active Faults in Japan, Active Faults in Japan: sheet map and inventories (Revised ed.), 437 pp., University of Tokyo Press, Tokyo, 1991 (in Japanese).

Stephenson, T. A. and A. Stephenson, The universal features of zonation between tide-marks on rocky coasts, J. Ecol., 37, 289-305, 1949.

Stephenson, T. A. and A. Stephenson, Life between tide marks on rocky shores, 452 pp., W. H. Freeman, San Fransisco, 1972.

Takeda, T., M. Matsubara, S. Sekine, T. Matsumoto, H. Matsubayashi, T. Kazakami, H. Hirose, T. Maeda, Y. Asano, H. Kimura, M. Matsumura, Y. Haryu, and K. Obara, An overview of the characteristics of the 2007 Noto Hanto earthquake revealed by the Hi-net/F-net data, Japan Geoscience Union Meeting 2007, Z255-P005, 2007.

Tobita, M., S. Ozawa, T. Nishimura, H. Yarai, H. Suito, M. Murakami, H. Une, A. Yamada, K. Takano, T. Yutsuda, M. Ishimoto, N. Ishikura, S. Kawamoto, and T. Amagai, Crustal deformation and fault model of the Noto Hanto Earthquake in 2007, Japan Geoscience Union Meeting 2007, Z255-P018, 2007.

Toda, S., Coulomb stresses imparted by the 25 March $2007 \mathrm{Mw}=6.6$ NotoHanto, Japan, earthquake explain its 'butterfly' distribution of aftershocks and suggest a heightened seismic hazard, Earth Planets Space, 2008 (in press).

Wessel, P. and W. H. F. Smith, New improved version of the Generic Mapping Tools Released, Eos Trans. AGU, 79, 579, 1998.

Y. Hiramatsu (e-mail: yoshizo@hakusan.s.kanazawa-u.ac.jp), K. Moriya, T. Kamiya, M. Kato, and T. Nishimura 